\title{
Uréia para Vacas em Lactação. 1. Consumo, Digestibilidade, Produção e Composição do Leite ${ }^{1}$
}

\author{
Rosângela Maria Nunes da Silva ${ }^{2}$, Rilene Ferreira Diniz Valadares ${ }^{3}$, Sebastião de Campos \\ Valadares Filho ${ }^{3}$, Paulo Roberto Cecon ${ }^{3}$, José Maurício de Souza Campos ${ }^{3}$, Gisele Andrade de \\ Oliveira $^{4}$, Antonia Santos Oliveira ${ }^{5}$
}

\begin{abstract}
RESUMO - Este trabalho foi conduzido, utilizando 15 vacas lactantes (Holandês x Gir) alimentadas à vontade com rações isoprotéicas, constituídas na base da matéria seca (MS) de $60 \%$ de silagem e $40 \%$ de concentrado, contendo $0 ; 0,7 ; 1,4$; e $2,1 \%$ de uréia, correspondentes aos teores de 2,08; 4,01; 5,76; e 8,07\% de proteína bruta na forma de compostos nitrogenados nãoprotéicos (NNP), com o objetivo de avaliar os consumos e as digestibilidades aparentes de matéria seca (MS), matéria orgânica (MO), proteína bruta (PB), extrato etéreo (EE), carboidratos totais (CHO) e fibra em detergente neutro (FDN) e os consumos de nutrientes digestíveis totais (NDT). Também foram avaliadas possíveis alterações na produção e composição do leite. As vacas apresentaram peso vivo médio inicial de $511,8 \mathrm{~kg}$ e foram distribuídas ao acaso entre tratamentos. O período experimental teve duração de 90 dias para cada vaca, iniciando-se imediatamente após o parto. A fibra em detergente ácido indigestível (FDAI) foi usada como indicador para a determinação da digestibilidade aparente dos nutrientes. Os resultados obtidos foram interpretados estatisticamente por análises de variância e regressão. A adição de quantidades crescentes de NNP à dieta apresentou efeito linear decrescente sobre os consumos de MS, MO, FDN, PB, EE, CHO e NDT. Não foram observados efeitos dos níveis de NNP sobre as digestibilidades aparentes de MS, MO, PB, CHO e FDN. Para o EE, foi observado efeito quadrático, sendo a máxima digestibilidade de $89,12 \%$ obtida com teor estimado de 4,73\% de NNP na MS. A produção máxima de leite, de $20,10 \mathrm{~kg} / \mathrm{dia}$, foi obtida com o teor estimado de 4,79\% de NNP, ou 0,7\% de uréia na MS total das rações. Observou-se redução linear do teor de gordura com o aumento dos teores de NNP nas rações, enquanto a proteína se comportou de forma quadrática, sendo o teor máximo de $3,4 \%$ estimado com $3,88 \%$ de NNP.
\end{abstract}

Palavras-chave: ingestão, nitrogênio não protéico (NNP)

\section{Urea for Dairy Cows. 1. Intake, Digestibility, Milk Production and Composition}

ABSTRACT - This work was carried out, using 15 dairy cows (Holstein x Gyr) full fed isoproteic diets with $60 \%$ silage and $40 \%$ concentrate in the dry matter (DM) basis and $0,0.7,1.4$, and $2.1 \%$ urea, correspondent to $2.08,4.01,5.76$, and $8.07 \%$ of crude protein levels in the form of non protein nitrogen compounds (NNP), with the objectives to evaluate the intakes and the apparent digestibilities of dry matter (DM), organic matter (OM), crude protein (CP), ether extract (EE), total carbohydrates (CHO) and neutral detergent fiber (NDF) and the total digestible nutrients (TDN) intakes. Possible changes on the milk production and composition were also evaluated. Cows averaging initial live weight of $511.8 \mathrm{~kg}$ were randomized allotted to the treatments. The experimental period last 90 days for each cow, starting immediately after calving. The indigestible acid detergent fiber (IADF) was used as marker to determine the nutrients apparent digestibility. The results were interpreted by variance and regression analyses. The addition of increasing NNP to the diet showed decreasing linear effect on the intakes of DM, OM, NDF, CP, EE, CHO and TDN. NNP levels did not affect the apparent digestibilities of DM, OM, CP, CHO and NDF. There was quadratic effect for EE, and the maximum digestibility of $89.12 \%$ was obtained with the estimated NNP content of $4.73 \%$ in DM. The maximum milk production, of $20.10 \mathrm{~kg} /$ day, was obtained with the estimated NNP content of $4.79 \%$, or $0.7 \%$ urea in dietary total DM. Linear reduction of fat content was observed as the dietary NNP contents increased, while there was a quadratic behavior for protein, with the maximum content of $3.4 \%$ estimated with $3.88 \%$ NNP.

Key Words: intake, Non-protein nitrogen (NPN)

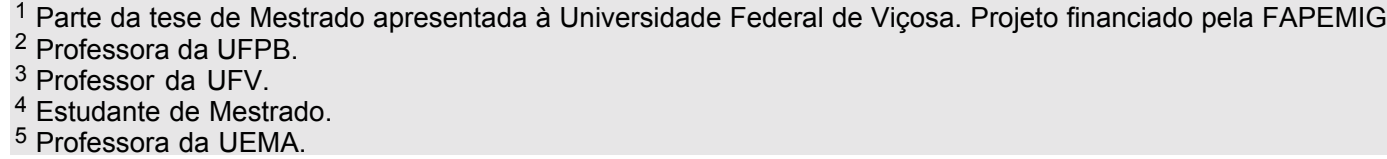

5 Professora da UEMA. 


\section{Introdução}

Na criação de ruminantes, tanto em confinamento quanto a pasto, a alimentação é responsável por grande parte dos custos (60 a 70\%). Portanto, é de fundamental importância conhecer as características dos alimentos e seu balanceamento nas rações, as quais devem ser formuladas para suprir as necessidades dos animais, explorando sua máxima capacidade digestiva. Um dos fatores mais críticos a ser alcançado é determinar a relação ideal entre volumoso e concentrado, principalmente no que diz respeito à relação entre energia e proteína.

Os suplementos protéicos são normalmente os componentes mais caros da ração para vacas leiteiras. O uso de uréia (composto nitrogenado nãoprotéico - NNP) pode representar uma alternativa para atender às exigências de vacas leiteiras em proteína, ao mesmo tempo que reduz os custos deste nutriente (LÓPEZ, 1984).

Para obtenção de altas produções de leite, as vacas devem ser alimentadas com quantidade suficiente de energia e de proteína (EKINCI e BRODERICK, 1997; VALADARES FILHO et al., 2000). De acordo com o NATIONAL RESEARCH COUNCIL - NRC (1989), a ingestão de matéria seca (IMS) é caracterizado como importante critério na formulação de dietas para vacas de alta produção.

Segundo SNIFFEN et al. (1993), a capacidade dos animais de consumir alimentos em quantidades suficientes para alcançar suas exigências de mantença e produção é um dos fatores mais importantes em sistemas de alimentação, em grande parte dependentes de volumosos.

Segundo VAN SOEST (1994), o controle da ingestão de alimentos é o resultado de vários mecanismos interrelacionados, que são integrados na resposta final de alimentação. A IMS é controlada por fatores fisiológicos de curto e longo prazo, em que o controle é realizado pelo balanço nutricional da dieta, especificamente relacionada à manutenção do equilíbrio energético, por fatores físicos, que estão associados à capacidade de distensão do próprio rúmen, e por fatores psicogênicos, que envolvem a resposta do animal a fatores inibidores ou estimuladores relacionados ao alimento e, ou, ao ambiente (SNIFFEN et al., 1993; MERTENS, 1994; e VAN SOEST, 1994).

Na estimativa do consumo, devem ser consideradas as limitações relativas ao animal, alimento e às condições de alimentação (MERTENS, 1992). Quando rações são formuladas para apresentar na composição elevado teor de fibra, ou baixa densidade energética em relação às exigências dos animais, $o$ consumo é limitado pelo efeito de "enchimento" do rúmen-retículo. Entretanto, se a densidade energética da ração é elevada, ou a concentração de fibra é baixa em relação às exigências dos animais, a ingestão passa a ser limitada pela demanda fisiológica de energia (MERTENS, 1994).

São vários os estudos que relataram alta correlação positiva entre a quantidade de fibra em detergente neutro (FDN) nos alimentos e o consumo de matéria seca (MS), além de fatores físicos limitando o consumo de alimento, havendo correlação negativa da extensão de degradação da FDN com o conteúdo de FDN. A indigestibilidade da MS é o principal fator que diminui o consumo de alimentos em ruminantes (CONRAD, 1966; NRC, 1989; MERTENS, 1994; VAN SOEST, 1994; e ALLEN, 1996).

MERTENS (1994) verificou que o consumo de MS e a produção de leite foram máximos para consumo de FDN de 1,25\% do peso vivo para vacas em meio e final de lactação. WOODFORD et al. (1986), trabalhando com vacas em meio de lactação, encontraram máxima produção de leite corrigido para $4 \%$ de gordura, quando os animais foram alimentados com dietas contendo em torno de $27 \%$ de FDN. Segundo OBA e ALLEN (1999), elevada digestibilidade da FDN da forragem aumenta significativamente a IMS e produção de leite.

Em dietas com níveis elevados de proteína degradável, observa-se possível toxidez pelo excesso de liberação de amônia no rúmen, que também interfere negativamente no consumo (BORGES, 1999a).

No início da lactação, é normal que o animal mobilize suas reservas corporais, devido a alta produção de leite, porém sua capacidade de suprir suas demandas energéticas é limitada. Em comparação com a energia, a quantidade de proteína que pode ser mobilizada das reservas corporais por dia é muito limitada (máximo de $145 \mathrm{~g}$ ), e a dieta é praticamente a única fonte de proteína para suprir as necessidades da vaca, sendo que a síntese microbiana no rúmen supre parte dessa proteína. Recomenda-se, então, concentração protéica de 18 a 19\% na MS da dieta nessa fase (BORGES, 1999b).

Segundo LUCCI (1997), a composição nitrogenada da dieta pode influir na taxa de gordura láctea: aumentos na concentração protéica da ração de $12-14 \%$ para $18 \%$ podem reduzir a porcentagem 
de gordura até $0,5 \%$, o que pode ser atribuído ao incremento do volume de leite produzido. No tocante à proteína láctea, pequenos acréscimos podem ser medidos, quando é aumentado o teor de proteína dietética.

HUBER e KUNG (1981) relataram que, no passado, a quantidade de NNP nas rações de ruminantes era calculada com base na uréia adicionada, porém vários alimentos, particularmente as silagens, contribuem com o NNP; portanto, essas fontes devem ser consideradas no cálculo da quantidade total presente na dieta.

HOLTER et al. (1968) verificaram que a uréia fornecida até o nível de 2,5\% em misturas de concentrados não apresentou efeitos prejudiciais significativos no consumo de alimento, em sua digestibilidade ou na produção de leite. Contudo, WILSON et al. (1975) observaram decréscimo no consumo de MS de uma ração completa contendo $2,3 \%$ de uréia (425 a $450 \mathrm{~g} / \mathrm{dia}$ ), quando a uréia foi administrada oralmente ou por intermédio da fístula ruminal.

Comparando uma ração constituída por uréia, sabugo de milho e outros subprodutos com outra ração composta por silagem de milho, alfafa, milho e farelo de soja, Peyton e Conrad (1982), citados por LÓPEZ (1984), observaram que o consumo de MS das duas dietas foi igual, porém os animais que receberam a primeira ração produziram menos leite, com menor teor de gordura e menos proteína que os animais alimentados com a outra ração. No trabalho de WOHLT e CLARK (1979), vacas leiteiras com produção média de $20 \mathrm{~kg}$ de leite por dia receberam, durante toda a lactação, silagem de milho e feno de alfafa suplementados com uréia ou farelo de soja; as rações continham de 9 a 14,5\% de proteína bruta (PB). Foi observado que a produção de leite corrigida para $4 \%$ de gordura e os teores de proteína e gordura do leite foram maiores para o nível de 11 a $12 \%$ de PB. A explicação para os melhores resultados obtidos com o farelo de soja deve-se, provavelmente, à maior quantidade de proteína dietética que escapou à degradação no rúmen.

O objetivo deste trabalho foi avaliar o efeito de quatro níveis de compostos nitrogenados não-protéicos (NNP) sobre os consumos e as digestibilidades de matéria seca (MS), matéria orgânica (MO), proteína bruta (PB), extrato etéreo (EE), carboidratos totais (CHO) e fibra em detergente neutro (FDN); além dos consumos de nutrientes digestíveis totais (NDT); e a produção e composição do leite.

\section{Material e Métodos}

O presente experimento foi realizado na Fazenda Experimental da Empresa de Pesquisa Agropecuária de Minas Gerais (EPAMIG), no município de Leopoldina - MG.

A cidade de Leopoldina está localizada na Zona da Mata, no Estado de Minas Gerais, a uma distância de $150 \mathrm{~km}$ da cidade de Viçosa, a 220 metros de altitude, $21^{\circ} 31^{\prime} 50^{\prime \prime}$ ' de latitude sul e $42^{0} 38^{\prime} 30^{\prime \prime}$ ' de latitude oeste. Seu clima é tropical úmido, apresentando temperaturas médias anuais com máximas de $39^{\circ} \mathrm{C}$ e mínimas de $11^{\circ} \mathrm{C}$. A precipitação pluviométrica é de $1200 \mathrm{~mm}$ anuais.

Foram utilizadas 15 vacas mestiças (Holandês $\mathrm{x}$ Gir), com peso médio de $511,8 \mathrm{~kg}$, distribuídas entre os tratamentos, segundo delineamento inteiramente casualizado, para atender a experimento simultâneo de avaliação de aspectos reprodutivos, sendo quatro vacas nos tratamentos 1,2 e 4 e três vacas no tratamento 3. O experimento teve início em 23/04/99 e se estendeu até 31/10/99, com duração de 90 dias para cada animal, iniciando-se imediatamente após o parto. Os animais foram mantidos em baias individuais, cobertas, providas de cocho e bebedouro individual e foram soltos de 12 às $14 \mathrm{~h}$ e de 20 às $5 \mathrm{~h} \mathrm{em}$ piquetes sem pastagem, objetivando minimizar estresse e problemas de casco.

As dietas, constituídas de volumoso e concentrado na proporção de 60:40, foram formuladas para serem isoprotéicas e continham $0 ; 0,7 ; 1,4 ;$ e $2,1 \%$ de uréia, correspondentes aos níveis de 2,$08 ; 4,01 ; 5,76$; e $8,07 \%$ de proteína bruta na forma de compostos nitrogenados não-protéicos (NNP), respectivamente, para os tratamentos 1, 2, 3 e 4. A composição percentual dos ingredientes encontra-se na Tabela 1; a composição química dos concentrados e da silagem de milho, na Tabela 2; e a composição química observada nas quatro rações, na Tabela 3.

O alimento, na forma de mistura completa, foi oferecido à vontade, duas vezes ao dia, de forma a permitir 5\% de sobras. As vacas foram adaptadas, de forma gradual, às rações contendo uréia, utilizandose $0,7 \%$ de uréia na primeira semana pós-parto, para o T2, 0,7 e 1,4\% de uréia na primeira e segunda semanas para o T3, e 0,$7 ; 1,4$; e $2,1 \%$ de uréia na primeira, segunda e terceira semanas, respectivamente, para o T4. Dessa forma, os 21 dias iniciais foram considerados como período de adaptação. Durante o período experimental, com duração de 10 
Tabela 1 - Composição percentual dos ingredientes utilizados nos tratamentos experimentais (\% na MS)

Table 1 - Percentage composition of the ingredients used in the experimental treatments (\% DM)

\begin{tabular}{|c|c|c|c|c|}
\hline \multirow[t]{2}{*}{$\begin{array}{l}\text { Ingredientes } \\
\text { Ingredients }\end{array}$} & \multicolumn{4}{|c|}{$\begin{array}{c}\text { Tratamentos } \\
\text { Treatments } \\
\end{array}$} \\
\hline & 1 & 2 & 3 & 4 \\
\hline $\begin{array}{l}\text { Silagem de milho } \\
\text { Corn silage }\end{array}$ & 60 & 60 & 60 & 60 \\
\hline $\begin{array}{l}\text { Fubá de milho } \\
\text { Corn meal }\end{array}$ & 18,31 & 22,19 & 26,07 & 29,95 \\
\hline $\begin{array}{l}\text { Farelo de soja } \\
\text { Soybean meal }\end{array}$ & 20,09 & 15,51 & 10,93 & 6,35 \\
\hline $\begin{array}{l}\text { Uréia } \\
\text { Urea }\end{array}$ & 0,00 & 0,70 & 1,40 & 2,10 \\
\hline $\begin{array}{l}\text { Mistura mineral }{ }^{1} \\
\text { Mineral mix }\end{array}$ & 1,60 & 1,60 & 1,60 & 1,60 \\
\hline
\end{tabular}

${ }^{1}$ Composição percentual (Percent composition) (Bovigold): Ca, 23; P, 9,0; S, 1,5; Mg, 2; Na, 4,8; Co, 0,01; Cu, 0,07; Fe, 0,2; I, 0,008; 2,66; $\mathrm{Zn}, 0,27,0 ;$ Se, 0,002; Mn, 0,125.

semanas, foram feitas pesagens dos animais, sendo a primeira realizada no dia do parto e as seguintes, uma vez por semana.

As vacas foram ordenhadas duas vezes ao dia e a produção de leite em cada ordenha, registrada durante os primeiros 90 dias pós-parto. Aos 30, $60 \mathrm{e}$ 90 dias do experimento, amostras de leite da $1^{\mathrm{a}}$ e $2^{\mathrm{a}}$ ordenhas foram coletadas e, posteriormente, compostas para determinação dos teores de proteína, conforme descrito por SILVA (1990) e gordura (PREGNOLATTO e PREGNOLATTO, 1985). O leite foi corrigido para o teor de $3,5 \%$ de gordura, conforme a equação: produção de leite corrigida $($ PLC $)=(0,432+0,1625 \times \%$ de gordura do leite $) \times$ $\mathrm{kg}$ de leite (SKLAN et al., 1992). A eficiência alimentar para cada vaca foi calculada pela divisão da produção média de leite pela ingestão média de matéria seca (VALADARES FILHO et al., 2000).

Durante toda fase experimental, as sobras foram retiradas e pesadas antes do fornecimento diário do alimento para determinação do consumo voluntário. As amostras diárias das sobras de cada animal, das silagens e dos concentrados foram acondicionadas em sacos plásticos e armazenadas a $-20^{\circ} \mathrm{C}$. Posteriormente, foram pré-secas e compostas semanalmente na base do peso seco. Ao final do experimento, as amostras individuais das sobras e dos alimentos oferecidos foram moídas em moinho de peneira de $1 \mathrm{~mm}$ de malha, acondicionadas em vidro com tampa e armazenadas para análises posteriores.
Às $8 \mathrm{~h}$ do $30^{\circ}$ dia e às $15 \mathrm{~h}$ do $38^{\circ}$ dia do período experimental, procedeu-se à coleta de fezes diretamente da ampola retal (VAGNONI et al., 1997). As amostras foram acondicionadas em sacos plásticos e armazenadas a $-20^{\circ} \mathrm{C}$. Ao término do período de coletas, as amostras foram descongeladas à temperatura ambiente, submetidas à pré-secagem em estufa de ventilação forçada a $65^{\circ} \mathrm{C}$, por 72 a $96 \mathrm{~h}$, e, posteriormente, moídas em moinho com peneira dotada de crivos de $1 \mathrm{~mm}$ de diâmetro, compostas por animal, e armazenadas em vidros para futuras análises químicas.

As análises laboratoriais foram realizadas nos Departamentos de Veterinária e de Zootecnia da Universidade Federal de Viçosa (UFV). Os teores de matéria seca (MS), matéria orgânica (MO), extrato etéreo (EE) e compostos nitrogenados totais (N-total) foram determinados conforme a técnica descrita por SILVA (1990) e o de a fibra em detergente neutro (FDN), segundo Van Soest (1967), citado por SILVA (1990).

A porcentagem de carboidratos totais $(\mathrm{CHO})$ foi obtida pela equação: $100-(\% \mathrm{~PB}+\% \mathrm{EE}+\%$ cinzas $)$. Para o cálculo dos nutrientes digestíveis totais (NDT), utilizou-se a equação descrita por SNIFFEN et al. (1992): $\mathrm{NDT}=(\mathrm{PBD}+\mathrm{CHOD})+2,25(\mathrm{EED})$, em que

Tabela 2 - Teores médios de matéria seca (MS), matéria orgânica (MO), proteína bruta (PB), compostos nitrogenados não-protéicos (NNP), extrato etéreo (EE), carboidratos totais (CHO) e fibra em detergente neutro (FDN) dos concentrados e da silagem de milho

Table 2 - Average contents of dry matter (DM), organic matter $(O M)$, crude protein $(C P)$, non protein nitrogen compounds (NPN), ether extract (EE), total carbohydrates (CHO) and neutral detergent fiber (NDF) of the concentrates and corn silage

\begin{tabular}{lrrrrr}
\hline & \multicolumn{5}{c}{$\begin{array}{c}\text { Concentrados } \\
\text { Concentrates }\end{array}$} \\
\cline { 2 - 5 } Itens & $\mathrm{Cl}$ & $\mathrm{C} 2$ & $\mathrm{C} 3$ & $\mathrm{C} 4$ & $\begin{array}{c}\text { Silagem } \\
\text { Silage }\end{array}$ \\
\hline MS \% & 84,97 & 84,85 & 84,95 & 84,18 & 30,04 \\
$\% D M$ & & & & & \\
MO $^{1}$ & 94,15 & 94,48 & 94,59 & 95,05 & 94,45 \\
$O M^{1}$ & & & & & \\
PB $^{1}$ & 24,20 & 24,20 & 24,20 & 24,20 & 6,30 \\
$C P$ & & & & & \\
NNP(\%PB) & 0,06 & 0,26 & 0,44 & 0,73 & 0,39 \\
$N P N(\% C P)$ & & & & & \\
EE $^{1}$ & 1,31 & 1,73 & 1,69 & 1,14 & 1,94 \\
CHO $^{1}$ & 68,64 & 68,55 & 68,70 & 69,71 & 86,21 \\
FDN $^{1}$ & 15,12 & 15,12 & 15,12 & 15,12 & 57,50 \\
$N D F$ & & & & & \\
\hline
\end{tabular}

${ }^{1}$ Porcentagem da MS (DM percentage). 
PBD, CHOD e EED significam, respectivamente, consumos de $\mathrm{PB}, \mathrm{CHO}$ e EE digestíveis. O teor de NNP, por sua vez, foi obtido pela metodologia descrita por Broderick em 1997 (comunicação pessoal), em que $10 \mathrm{~g}$

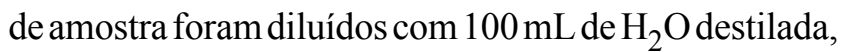
homogeneizados em liqüidificador e filtrados em duas camadas de gaze. Posteriormente, $20 \mathrm{~mL}$ do filtrado foram tratados com $5 \mathrm{~mL}$ de ácido tricloroacético (TCA) a $25 \%$, centrifugados a $30.000 \times \mathrm{g}$, e o sobrenadante, analisado para $\mathrm{N}$ total, conforme SILVA (1990).

Para determinação dos coeficientes de digestibilidade aparente dos nutrientes, foi utilizada a fibra em detergente ácido indigestível (FDAI) como indicador interno (COCHRAN et al., 1986), determinando-se o FDA remanescente após 144 horas de incubação in situ (CRAIG et al., 1984).

Os resultados foram avaliados por meio de análises de variância e regressão, utilizando-se o programa SAEG - Sistema de Análises Estatísticas e Genéticas (UNIVERSIDADE FEDERAL DE VIÇOSA UFV, 1998). Os modelos foram escolhidos com base na significância dos coeficientes de regressão, utilizando-se o teste de F, e no coeficiente de determina-

Tabela 3 - Teores médios de matéria seca (MS), matéria orgânica (MO), proteína bruta (PB), compostos nitrogenados não-protéicos (NNP), extrato etéreo $(\mathrm{EE})$, carboidratos totais $(\mathrm{CHO})$, fibra em detergente neutro (FDN) e nutrientes digestíveis totais (NDT), obtidos para as quatro rações experimentais

Table 3 - Average contents of dry matter (DM), organic matter $(O M)$, crude protein $(C P)$, non protein nitrogen compounds (NPN), ether extract (EE), total carbohydrates (CHO), neutral detergent fiber (NDF) and total digestible nutrients (TDN) obtained for the four experimental diets

\begin{tabular}{lcccc}
\hline & \multicolumn{4}{c}{$\begin{array}{c}\text { Rações experimentais } \\
\text { Experimental diets }\end{array}$} \\
\cline { 2 - 5 } Itens & $\mathrm{R} 1$ & $\mathrm{R} 2$ & $\mathrm{R} 3$ & $\mathrm{R} 4$ \\
\hline MS \% & 53,03 & 52,84 & 50,92 & 50,89 \\
$\%$ DM & & & & \\
MO $^{1}$ & 94,33 & 94,46 & 94,59 & 95,05 \\
$O M$ & & & & \\
PB $^{1}$ & 13,46 & 13,46 & 13,46 & 13,46 \\
$C P$ & & & & \\
NNP (\% PB) & 2,08 & 4,01 & 5,76 & 8,07 \\
$N P N(\% C P)$ & 1,69 & 1,85 & 1,84 & 1,62 \\
EE $^{1}$ & 79,18 & 79,45 & 79,29 & 79,97 \\
CHO & 1 & 40,55 & 40,55 & 40,55 \\
FDN $^{1}$ & 40,55 & & \\
$N D F$ & 73,99 & 74,15 & 83,93 & 77,36 \\
NDT & & & & \\
$T D N$ & & &
\end{tabular}

${ }^{1}$ Porcentagem da MS (DM percentage). ção $\mathrm{R}^{2}$, que foi calculado com base na divisão da Soma do Quadrado (SQ) da regressão pela SQ do Tratamento $\left(\mathrm{R}^{2}=\right.$ SQRegressão/SQTratamento $)$.

\section{Resultados e Discussão}

As médias referentes aos consumos de MS, MO, FDN, EE, PB, CHO e NDT, expressos em quilogramas por dia (kg/dia), e aos consumos de MS e FDN, em porcentagem do peso vivo ( $\% \mathrm{PV}$ ), bem como os respectivos coeficientes de variação, são apresentados na Tabela 4, enquanto as equações de regressão e os coeficientes de determinação são demonstrados na Tabela 5.

Ao se elevarem os níveis de NNP nas rações, os consumos de MS, expressos em $\mathrm{kg} /$ dia e \% $\mathrm{PV}$, diminuíram linearmente $(\mathrm{P}<0,05)$. $\mathrm{O}$ menor consumo de MS foi provavelmente causado pelos efeitos metabólicos da uréia e, ou, à pouca palatabilidade ao alimento, à medida que se elevou o teor de uréia na ração, conforme HUBER e COOK (1972), que atribuíram a redução no consumo em dietas com alto nível de uréia no concentrado ( 1 a $3 \%$ ) à pouca palatabilidade desta, e não a efeitos ruminais ou pós-ruminais.

WILSON et al. (1975) observaram decréscimo no consumo de MS de uma ração completa contendo $2,3 \%$ de uréia ( $425 \mathrm{a} 450 \mathrm{~g} / \mathrm{dia})$, quando a uréia foi administrada oralmente ou por meio da fístula ruminal. Esses autores observaram que o aumento da quantidade de uréia de 1 para $3 \%$ acarretou em acréscimos nas concentrações de amônia no rúmen e de uréia no sangue e na saliva, enquanto o nível de amônia no sangue não foi alterado. Foi sugerido que metabólitos intermediários do catabolismo da uréia podem em parte ser os responsáveis pela depressão na ingestão de alimentos, quando os níveis de uréia na ração total estão acima de $1 \%$. Este fato também está de acordo com CHALUPA et al. (1979) e HUBER e KUNG (1981), os quais consideraram ser a amônia, pela sua toxidez em nível celular, o mais provável metabólito responsável pela redução alimentar.

Já KERTZ et al. (1982) concluíram que vacas não-expostas anteriormente à NNP precisam de várias semanas de fornecimento para que um sinal fisiológico negativo de retorno seja estabelecido, pelo qual os animais possam detectar o alimento contendo uréia como indesejável.

Os consumos de $\mathrm{MO}$, EE, $\mathrm{PB}$ e $\mathrm{CHO}$, expressos em $\mathrm{kg} /$ dia, diminuíram linearmente $(\mathrm{P}<0,05)$ com o 
Tabela 4 - Consumos médios diários de matéria seca (MS), matéria orgânica (MO), fibra em detergente neutro (FDN), extrato etéreo (EE), proteína bruta (PB), carboidratos totais ( $\mathrm{CHO}$ ) e nutrientes digestíveis totais (NDT), em função dos níveis de compostos nitrogenados não-protéicos (NNP) das rações, observados durante o período de digestibilidade (30 ao $38^{\circ}$ dia pós-parto), coeficiente de variação $(C V)$ e nível de probabilidade $(P)$ dos efeitos linear (L) e quadrático $(Q)$

Table 4 - Average daily intakes of dry matter (DM), organic matter (OM), neutral detergent fiber (NDF), ether extract (EE), crude protein $(C P)$, total carbohydrates (CHO), and total digestible nutrients (TDN), in function of the non protein nitrogen compounds (NPN) of the diets, observed during the digestibility period (from $30^{\text {th }}$ to $38^{\text {th }}$ day post calving), coefficient of variation (CV) and level of probability $(P)$ of linear $(L)$ and quadratic $(Q)$ effects

\begin{tabular}{|c|c|c|c|c|c|c|c|}
\hline \multirow[t]{2}{*}{$\begin{array}{l}\text { Variáveis } \\
\text { Variables }\end{array}$} & \multicolumn{4}{|c|}{$\begin{array}{c}\text { Teores de NNP (\%) } \\
\text { NPN contents }(\%)\end{array}$} & \multirow[t]{2}{*}{ CV $(\%)$} & \multicolumn{2}{|c|}{$\mathrm{P}$} \\
\hline & 2,08 & 4,01 & 5,76 & 8,07 & & $\mathrm{~L}$ & $\mathrm{Q}$ \\
\hline \multicolumn{8}{|c|}{$\begin{array}{c}\text { Consumos }(\mathrm{kg} / \mathrm{dia}) \\
\text { Intakes }(\mathrm{kg} / \text { day })\end{array}$} \\
\hline $\mathrm{MS}(D M)$ & 16,04 & 16,49 & 11,64 & 11,93 & 17,32 & 0,0073 & $\mathrm{~ns}$ \\
\hline $\mathrm{MO}(O M)$ & 15,13 & 15,58 & 11,02 & 11,35 & 17,21 & 0,0081 & $\mathrm{~ns}$ \\
\hline $\mathrm{FDN}(N D F)$ & 6,68 & 6,84 & 4,69 & 5,22 & 19,64 & 0,0234 & $\mathrm{~ns}$ \\
\hline $\mathrm{EE}$ & 0,29 & 0,33 & 0,24 & 0,23 & 15,68 & 0,0180 & $\mathrm{~ns}$ \\
\hline $\mathrm{PB}(C P)$ & 2,29 & 2,33 & 1,63 & 1,49 & 16,16 & 0,0008 & $\mathrm{~ns}$ \\
\hline $\mathrm{CHO}$ & 12,61 & 12,97 & 9,11 & 9,56 & 17,61 & 0,0104 & $\mathrm{~ns}$ \\
\hline $\operatorname{NDT}(T D N)$ & 11,87 & 12,10 & 9,74 & 9,12 & 13,39 & 0,0036 & $\mathrm{~ns}$ \\
\hline \multicolumn{8}{|c|}{$\begin{array}{c}\text { Consumos }(\% P V) \\
\text { Intakes }(\% L W)\end{array}$} \\
\hline $\mathrm{MS}(D M)$ & 3,29 & 3,09 & 2,47 & 2,35 & 16,46 & 0,0026 & $\mathrm{~ns}$ \\
\hline $\mathrm{FDN}(N D F)$ & 1,37 & 1,28 & 0,99 & 1,03 & 17,99 & 0,0097 & $\mathrm{~ns}$ \\
\hline
\end{tabular}

ns: não-significativo em nível de $5 \%$ de probabilidade pelo teste $\mathrm{F}$. ns: not significant at $5 \%$ of probability by $F$ test.

aumento nas proporções de NNP nas rações, refletindo o mesmo comportamento verificado para a MS, o que pode ser explicado pelo menor consumo de MS, quando os animais receberam rações com maiores quantidades de uréia.

Considerando vacas de $500 \mathrm{~kg}$ de peso vivo, para produção de $20 \mathrm{~kg}$ de leite, as exigências de PB e NDT seriam, respectivamente, de 2,044 e 9,72 kg, segundo o NRC (1989).

O consumo de $\mathrm{CHO}$, em média $11,06 \mathrm{~kg} / \mathrm{dia}$, foi reduzido linearmente pelo aumento dos níveis de NNP na dieta. A redução linear $(\mathrm{P}<0,05)$ do consumo de FDN, expressa em kg/dia e \%PV, pode ser atribuída à diminuição no consumo de MS. Este fato também se refletiu sobre o consumo de NDT em $\mathrm{kg} / \mathrm{dia}$, que decresceu linearmente $(\mathrm{P}<0,05)$ com o nível de NNP, em virtude, possivelmente, de menor ingestão de carboidratos totais, associada à redução na atividade de microrganismos celulolíticos. Observou-se, neste experimento, média de $1,16 \%$ no consumo de FDN em $\% \mathrm{PV}$, nível próximo ao valor de $1,25 \% \mathrm{PV}$, considerado ótimo por MERTENS (1992), para vacas leiteiras.

Os coeficientes de digestibilidade (CD) aparentes de MS, MO, FDN, EE, PB e CHO, com seus respectivos coeficientes de variação, e a equação de regressão ajustada do CDEE, em função do NNP das rações, encontram-se na Tabela 6.
Não foi observado efeito $(\mathrm{P}>0,05)$ dos níveis de NNP sobre as digestibilidades de MS, MO, FDN, PB e CHO. O nível de consumo é um fator que pode influenciar a digestibilidade da dieta (RAMOS et al.,

Tabela 5 - Equações de regressão ajustadas para os
consumos diários dos nutrientes, em função
dos teores de compostos nitrogenados não-
protéicos (NNP) das rações, obtidas para o
período de digestibilidade $\left(30^{\circ}\right.$ ao $38^{\circ}$ dia pós-
parto), e os respectivos coeficientes de
determinação ( ${ }^{2}$ )


Tabela 6 - Coeficientes de digestibilidade aparente de matéria seca (MS), matéria orgânica (MO), fibra em detergente neutro (FDN), extrato etéreo (EE), proteína bruta (PB) e carboidratos totais (CHO), em função dos níveis de compostos nitrogenados não-protéicos (NNP) das rações, coeficiente de variação $(C V)$ e nível de probabilidade $(P)$ dos efeitos linear $(\mathrm{L})$ e quadrático $(\mathrm{Q})$

Table 6 - Coefficients of apparent digestibility of dry matter (DM), organic matter (OM), neutral detergent fiber (NDF), ether extract (EE), crude protein $(\mathrm{CP})$ and total carbohydrates $(\mathrm{CHO})$, in function of the non protein nitrogen compounds (NPN) of the diets, coefficient of variation (CV) and level of probability $(P)$ of linear $(L)$ and quadratic $(Q)$ effects

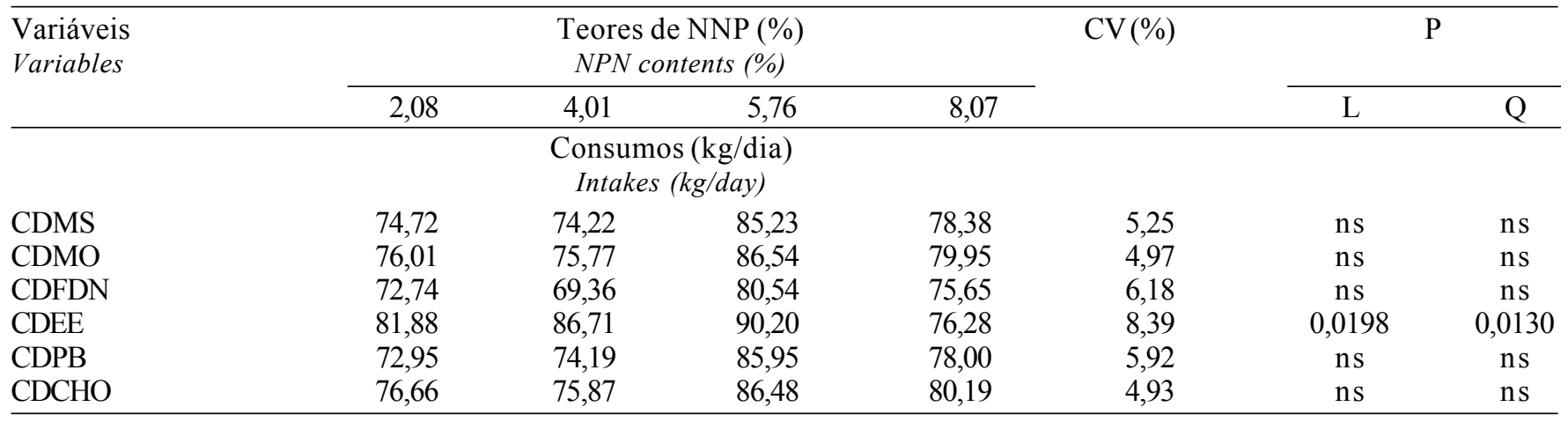

ns: não-significativo a $5 \%$ de probabilidade pelo teste $\mathrm{F}$ (ns: not significant at $5 \%$ of probability by $\mathrm{F}$ test).

CDEE $=64,1807+10,541$ NNP $-1,11359$ NNP $^{2} \quad R^{2}=0,9217$

2000), porém esse efeito não foi constatado neste experimento. Com exceção do EE, que apresentou comportamento quadrático, o máximo valor estimado de $89,12 \%$ com $4,73 \%$ de NNP na MS.

A digestibilidade média da MS da dieta de 78,14\% foi superior àquela observada por AROEIRA et al. (1995), ao trabalharem com vacas mestiças Holandês x Zebu alimentadas à base de cana-de-açúcar com $1 \%$ de uréia, suplementadas com farelo de algodão.

A digestibilidade média da PB no presente experimento foi de $77,77 \%$, a qual está próxima à obtida por AROEIRA et al. (1995), que foi de 78,6\%, e superior à observada por VALADARES FILHO et al. (2000), que correspondeu a 63,5\%. Esses últimos autores observaram aumento linear na digestibilidade aparente da PB, quando a silagem de alfafa foi substituída por espiga de milho de alta umidade moída, farelo de soja e uréia, o que, provavelmente, foi atribuído a aumento da digestibilidade dos últimos componentes.

BHATTACHARYA e KHAN (1973), quando substituíram farelo de soja por uréia até o nível de $2 \%$, não constataram diferenças nos coeficientes de digestibilidade para MS, PB e EE. O mesmo foi observado por MAYER et al. (1997) e SANTOS et al. (1998), ao trabalharem com vacas alimentadas com ração contendo farelo de soja, farinha de peixe e uréia $(0,8 \%)$.

Constam nas Tabelas 7 e 8 os resultados médios referentes aos consumos de MS, expressos em quilo- gramas por dia $(\mathrm{kg} /$ dia $)$ e em porcentagem de peso vivo $(\% \mathrm{PV})$, produção de leite $(\mathrm{kg} / \mathrm{dia})$ e eficiência (kg leite/kgMS ), e suas respectivas equações de regressão ajustadas e coeficientes de determinação, em função dos níveis de NNP para as 10 semanas experimentais. Para as variáveis citadas na Tabela 7 , utilizou-se a técnica de superfície de resposta, não sendo verificado efeito de semana e nem da interação semana $x$ NNP $(P>0,05)$.

A partir do período de adaptação dos animais à dieta, ou seja, entre 21 e 84 dias de lactação, foi observado comportamento quadrático $(\mathrm{P}<0,05)$ para os consumos de MS, bem como para produção de leite, obtendo-se valores máximos de $16,2 \mathrm{~kg} / \mathrm{dia}$ e $3,18 \% \mathrm{PV}$, para os consumos de MS, e 20,10 kg/dia, para produção de leite, com os níveis de 3,0; 2,44; e $4,79 \%$ de NNP. Entretanto, a eficiência alimentar apresentou efeito linear crescente $(\mathrm{P}<0,01)$ com o aumento nas proporções de NNP nas rações durante as dez semanas experimentais.

SUSMEL et al. (1995), trabalhando com vacas lactantes, observaram que as maiores produções de leite foram obtidas com a adição de uréia na ração, atribuindo-se à melhor utilização da fibra dietética. Entretanto, HOLTER et al. (1968), fornecendo uréia nos concentrados até o nível de $2,5 \%$, não encontraram efeito na produção de leite.

As médias referentes à produção de leite corrigida para 3,5\% de gordura e à sua composição, bem como os coeficientes de variação, as equações de regressão e os coeficientes de determinação, encontram- 
Tabela 7 - Consumos médios de matéria seca (MS), produção de leite (PL) e eficiência (kg leite/kg MS), obtidos em função dos níveis de NNP nas rações, para as 10 semanas experimentais

Table 7 - Average contents of dry matter (DM), milk production (MP) and efficiency ( $\mathrm{kg}$ milk/kg DM), in function of the dietary non protein nitrogen compounds (NPN), for the 10 experimental weeks

\begin{tabular}{|c|c|c|c|c|c|c|c|c|c|c|}
\hline \multirow[t]{2}{*}{$\begin{array}{l}\text { Níveis de NNP (\%) } \\
\text { NNP levels }\end{array}$} & \multicolumn{10}{|c|}{$\begin{array}{l}\text { Dias } \\
\text { Days }\end{array}$} \\
\hline & 21 & 28 & 35 & 42 & 49 & 56 & 63 & 70 & 77 & 84 \\
\hline & \multicolumn{10}{|c|}{$\begin{array}{l}\text { CMS (kg/dia) } \\
D M I(k g / \text { day })\end{array}$} \\
\hline 2,08 & 15,6 & 16,2 & 15,1 & 16,1 & 16,0 & 16,3 & 14,1 & 15,3 & 15,7 & 16,3 \\
\hline 4,01 & 14,4 & 16,0 & 16,5 & 17,1 & 17,5 & 16,7 & 17,7 & 18,1 & 17,8 & 17,9 \\
\hline 5,76 & 13,3 & 13,2 & 11,4 & 11,6 & 13,1 & 13,9 & 14,2 & 13,9 & 14,1 & 14,6 \\
\hline \multirow[t]{2}{*}{8,07} & 13,1 & 12,2 & 11,4 & 11,1 & 11,2 & 9,8 & 10,9 & 10,7 & 11,4 & 11,0 \\
\hline & \multicolumn{10}{|c|}{$\begin{array}{l}\text { CMS }(\% \mathrm{PV}) \\
D M I(\% L W)\end{array}$} \\
\hline 2,08 & 3,19 & 3,33 & 3,10 & 3,24 & 3,19 & 3,30 & 2,88 & 3,07 & 3,11 & 3,20 \\
\hline 4,01 & 2,84 & 3,07 & 3,07 & 3,16 & 3,27 & 3,21 & 3,18 & 3,25 & 3,17 & 3,15 \\
\hline 5,76 & 2,81 & 2,79 & 2,44 & 2,46 & 2,76 & 2,90 & 2,94 & 2,88 & 2,94 & 3,05 \\
\hline \multirow[t]{2}{*}{8,07} & 2,57 & 2,43 & 2,24 & 2,18 & 2,19 & 1,95 & 2,15 & 2,10 & 2,22 & 2,14 \\
\hline & \multicolumn{10}{|c|}{$\begin{array}{l}\text { PL (kg/dia) } \\
M P(k g / \text { day })\end{array}$} \\
\hline 2,08 & 18,4 & 18,1 & 18,6 & 18,3 & 17,7 & 18,2 & 16,8 & 16,8 & 17,4 & 17,6 \\
\hline 4,01 & 20,9 & 21,0 & 21,9 & 21,8 & 21,4 & 22,0 & 22,1 & 20,9 & 20,6 & 21,0 \\
\hline 5,76 & 17,5 & 18,1 & 18,0 & 16,1 & 17,9 & 18,3 & 18,4 & 19,0 & 18,8 & 19,3 \\
\hline \multirow[t]{2}{*}{8,07} & 19,1 & 19,8 & 18,4 & 18,3 & 17,8 & 17,0 & 17,0 & 16,5 & 16,4 & 16,9 \\
\hline & \multicolumn{10}{|c|}{$\begin{array}{l}\text { Eficiência (kg leite/kg MS) } \\
\text { Efficiency (kg milk/kg DM) }\end{array}$} \\
\hline 2,08 & 1,19 & 1,12 & 1,23 & 1,16 & 1,10 & 1,11 & 1,20 & 1,10 & 1,11 & 1,10 \\
\hline 4,01 & 1,45 & 1,33 & 1,36 & 1,30 & 1,23 & 1,28 & 1,27 & 1,18 & 1,20 & 1,24 \\
\hline 5,76 & 1,28 & 1,38 & 1,61 & 1,43 & 1,40 & 1,37 & 1,35 & 1,38 & 1,36 & 1,35 \\
\hline 8,07 & 1,49 & 1,70 & 1,63 & 1,68 & 1,71 & 1,76 & 1,57 & 1,55 & 1,46 & 1,55 \\
\hline
\end{tabular}

Tabela 8 - Equações de regressão ajustadas para os consumos médios semanais de matéria seca (CMS), produção de leite $(P L)$ e eficiência (EFI), em função dos níveis de compostos nitrogenados não-protéicos (NNP) das rações, observados para as 10 semanas do experimento, e os respectivos coeficientes de determinação $\left(R^{2} / r^{2}\right)$

Table 8 - Fitted regression equations for the weekly average dry matter intakes (DMI), milk production (MP) and efficiency (EFI), in function of the dietary non protein nitrogen compounds (NPN), for the 10 experimental weeks, and the respective coefficients of determination $\left(R^{2} / r^{2}\right)$

\begin{tabular}{|c|c|c|}
\hline $\begin{array}{l}\text { Variáveis } \\
\text { Variables }\end{array}$ & $\begin{array}{l}\text { Equações } \\
\text { Equations }\end{array}$ & $\mathrm{R}^{2} / \mathrm{r}^{2}$ \\
\hline $\begin{array}{l}\text { CMS ( kg/dia }) \\
D M I(k g / \text { day })\end{array}$ & $\hat{\mathrm{Y}}=14,3867+1,2077 * \mathrm{NNP}-0,201106 * * \mathrm{NNP}^{2}$ & 0,8602 \\
\hline $\begin{array}{l}\text { CMS }(\% \mathrm{PV}) \\
D M I(\% L W)\end{array}$ & $\hat{\mathrm{Y}}=2,99447+0,149039 * * * \mathrm{NNP}-0,030525 * * \mathrm{NNP}^{2}$ & 0,9949 \\
\hline $\begin{array}{l}\mathrm{PL}(\mathrm{kg} / \mathrm{dia}) \\
M P(\mathrm{~kg} / \text { day })\end{array}$ & $\hat{\mathrm{Y}}=14,3138+2,42023 * * \mathrm{NNP}-0,252826 * * \mathrm{NNP}^{2}$ & 0,4930 \\
\hline $\begin{array}{l}\text { EFI ( } \mathrm{kg} \text { leite/kg MS }) \\
\text { EFI ( } \mathrm{kg} \text { milk/kg DM) }\end{array}$ & $\hat{\mathrm{Y}}=0,0771522+0,975147 * * \mathrm{NNP}$ & 0,9934 \\
\hline
\end{tabular}


Tabela 9 - Produção de leite corrigida (PLG) para 3,5\% de gordura (G), teores e quantidades de G e proteína bruta (PB) do leite, em função dos teores de compostos nitrogenados não-protéicos (NNP) das rações, coeficiente de variação (CV) e nível de probabilidade $(P)$ dos efeitos linear $(L)$ e quadrático $(Q)$

Table 9 - Milk production corrected (MPC) for 3.5\% fat (F), milk $F$ and crude protein (CP) contents and amounts, in function of the dietary non protein nitrogen compounds contents (NPN), coefficients of variation (CV) and level of probability $(P)$ of linear $(L)$ and quadratic (Q) effects

\begin{tabular}{|c|c|c|c|c|c|c|c|}
\hline \multirow[t]{2}{*}{$\begin{array}{l}\text { Variáveis } \\
\text { Variables }\end{array}$} & \multicolumn{4}{|c|}{$\begin{array}{c}\text { Teores de NNP (\%) } \\
N P N \text { contents }(\%)\end{array}$} & \multirow[t]{2}{*}{ CV $(\%)$} & \multicolumn{2}{|c|}{$\mathrm{P}$} \\
\hline & 2,08 & 4,01 & 5,76 & 8,07 & & $\mathrm{~L}$ & Q \\
\hline & & $\begin{array}{r}\text { Consu } \\
\text { Intal }\end{array}$ & $\begin{array}{l}\mathrm{g} / \mathrm{dia}) \\
(\mathrm{day})\end{array}$ & & & & \\
\hline $\begin{array}{l}\operatorname{PLG}(\mathrm{kg} / \mathrm{dia}) \\
M P C(\mathrm{~kg} / \text { day })\end{array}$ & 21,18 & 24,92 & 20,63 & 18,83 & 15,94 & 0,0979 & $\mathrm{~ns}$ \\
\hline $\begin{array}{l}\mathrm{G}(\%) \\
F(\%)\end{array}$ & 4,65 & 4,50 & 4,29 & 3,90 & 14,60 & 0,0391 & $\mathrm{~ns}$ \\
\hline $\begin{array}{l}\mathrm{G}(\mathrm{g} / \text { dia }) \\
F(\text { g/day })\end{array}$ & 809,94 & 933,23 & 789,31 & 701,95 & 19,92 & $\mathrm{~ns}$ & $\mathrm{~ns}$ \\
\hline $\begin{array}{l}\mathrm{PB}(\%) \\
C P(\%)\end{array}$ & 3,22 & 3,55 & 3,07 & 2,69 & 10,66 & 0,0841 & 0,0366 \\
\hline $\begin{array}{l}\mathrm{PB}(\mathrm{g} / \mathrm{dia}) \\
C P(\mathrm{~g} / \mathrm{day})\end{array}$ & 559,69 & 731,48 & 553,12 & 486,82 & 16,41 & 0,0489 & 0,0286 \\
\hline
\end{tabular}

ns: não-significativo em nível de $5 \%$ de probabilidade pelo teste $\mathrm{F}$.

ns: not significant at $5 \%$ of probability by $F$ test.

se, respectivamente, nas Tabelas 9 e 10.

Quando corrigida para 3,5\% de gordura, a produção de leite decresceu linearmente $(\mathrm{P}<0,05)$ com o aumento dos níveis de NNP na ração. As menores ingestões de MS e MO, com elevação dos teores de NNP neste experimento, poderiam implicar em menores produções de leite; além disso, quantidades maiores de NNP na dieta aumentam mais rapidamente a formação de amônia ruminal.

$\mathrm{O}$ teor de gordura do leite, expresso em \%, diminuiu linearmente $(\mathrm{P}<0,05)$, ao se elevarem os níveis de NNP na dieta, o que, provavelmente, é atribuído à redução no consumo de MS, quando os níveis de uréia na ração se elevaram.

Contrariamente, SUSMEL et al. (1995) obtiveram os maiores teores de gordura no leite, quando a uréia foi o suplemento da ração para vacas leiteiras, o que poderia ser conseqüência de melhor utilização da fibra dietética, a qual provê os precursores para a síntese de lipídios na glândula mamária. VALADARES FILHO et al. (2000), utilizando $8,5 \%$ de PB na forma de NNP em rações

Tabela 10 - Equações de regressão ajustadas para a produção de leite corrigida (PLG) para $3,5 \%$ de gordura $(G)$ e para os teores e quantidades de $G$ e proteína bruta (PB) do leite, em função dos teores de compostos nitrogenados não- protéicos (NNP) das rações, e os respectivos coeficientes de determinação $\left(R^{2} / r^{2}\right)$

Table 10 - Fitted regression equations for the milk production corrected (MPC) for $3.5 \%$ fat (F) and for the milk $F$ and crude protein (CP) contents and amounts, in function of the dietary non protein nitrogen compounds contents (NPN), and the respective coefficients of determination $\left(R^{2} / r^{2}\right)$

\begin{tabular}{lcc}
\hline Variáveis & \multicolumn{1}{c}{$\begin{array}{c}\text { Equações } \\
\text { Equations }\end{array}$} & $\mathrm{R}^{2} / \mathrm{r}^{2}$ \\
Variables & $\mathrm{Y}=24,2912-0,57799 \mathrm{NNP}$ & 0,3314 \\
\hline $\mathrm{PLG}(\mathrm{kg} /$ dia $)$ & $\mathrm{Y}=4,96662-0,127155 \mathrm{NNP}$ & 0,9737 \\
$\begin{array}{l}M P C(\mathrm{~kg} / \text { day }) \\
\mathrm{G}(\%)\end{array}$ & $\mathrm{Y}=2,7551+0,336078 \mathrm{NNP}-0,0432 \mathrm{NNP}^{2}$ & 0,8694 \\
$F(\%)$ & $\mathrm{Y}=373,067+131,27 \mathrm{NNP}-14,7809 \mathrm{NNP}^{2}$ & 0,6567 \\
$\mathrm{~PB}(\%)$ & & \\
$C P(\%)$ & & \\
$\mathrm{PB}(\mathrm{g} /$ dia $)$ & & \\
$C P($ day $)$ & & \\
\hline
\end{tabular}


contendo aproximadamente $17 \%$ de PB, observaram constância no teor de gordura do leite até $50 \%$ de concentrado.

Observou-se que a produção de gordura do leite, expressa em g/dia, não foi influenciada $(\mathrm{P}>0,05)$ pelo uso de diferentes níveis de NNP, apresentando valor médio de 806,60 g/dia, o que está de acordo com CANNAS et al. (1998).

Com relação à proteína do leite, em \% e g/dia, foi observado efeito quadrático em função dos níveis de NNP, obtendo-se valores máximos de 3,4\% e 664,44 g/dia para os teores de 3,88 e $4,44 \%$ de NNP, respectivamente.

Segundo JONKER et al. (1999), dietas com baixos níveis de energia e excesso dos requerimentos de PDR em relação as exigências da vaca podem resultar em decréscimo na produção de leite e, conseqüentemente, da secreção de proteína do mesmo. De acordo com ROSELER et al. (1993), a produção de proteína do leite foi positivamente relacionada à produção de leite, o que também foi evidenciado neste experimento.

Na Tabela 11, são apresentados os pesos médios das vacas, expressos em quilogramas $(\mathrm{kg})$, em função dos teores de NNP na dieta, avaliados em diferentes dias após o início da lactação.

Verificou-se que o peso dos animais não foi afetado significativamente $(\mathrm{P}>0,05)$ pelos teores de NNP da dieta, durante o período experimental. Segundo BORGES (1999b), até os 70 primeiros dias de lactação, as vacas de leite mobilizam reser-

Tabela 11 - Pesos médios $(\mathrm{kg}$ ) das vacas, em função dos teores de compostos nitrogenados nãoprotéicos (NNP) das rações, avaliados em diferentes dias após o início da lactação

Table 11 - Average weights $(\mathrm{kg})$ of cows, in function of the dietary non protein nitrogen compounds contents (NPN), evaluated at different days after the beginning of lactation

\begin{tabular}{lrrrr}
\hline \multirow{2}{*}{ Dias } & \multicolumn{4}{c}{$\begin{array}{c}\text { Teores de NNP (\%) } \\
\text { NPN contents }\end{array}$} \\
\cline { 2 - 5 } & 2,08 & 4,01 & 5,76 & 8,07 \\
\hline 21 & 492,16 & 520,00 & 476,33 & 511,25 \\
49 & 505,55 & 538,75 & 479,50 & 507,38 \\
77 & 507,63 & 562,50 & 484,83 & 514,88 \\
84 & 510,50 & 564,75 & 484,67 & 517,25 \\
\hline
\end{tabular}

$\mathrm{CV}=15,23 \%$.

Rev. bras. zootec., 30(5):1639-1649, 2001 vas corporais e perdem peso para suprir o balanço energético negativo, o que não se evidenciou neste experimento, permitindo inferir que o consumo dos nutrientes foi suficiente para atender às exigências para mantença e produção das vacas no terço inicial de lactação.

\section{Conclusões}

A adição de níveis crescentes de NNP, em substituição à proteína verdadeira, reduziu o consumo de nutrientes, porém, não foi observado efeito sobre as digestibilidades de $\mathrm{MS}$, MO, FDN, $\mathrm{PB}$ e CHO, para as vacas no terço inicial de lactação.

A produção máxima de leite, de $20,10 \mathrm{~kg} / \mathrm{dia}$, foi estimada com o teor de $4,79 \%$ de NNP, ou $0,7 \%$ de uréia na MS total das rações.

O máximo teor de proteína do leite, 3,4\%, foi estimado para 3,88\% de NNP na MS das rações.

\section{Referências Bibliográficas}

ALLEN, M.S. 1996. Physical constraints on voluntary intake of forage by ruminants. J. Anim. Sci., 74(12):3063-3075.

AROEIRA, L.J.M., LOPES, F.C.F., DAYRELL, M.S. 1995. Digestibilidade, degradabilidade e taxa de passagem da canade-açúcar mais uréia e do farelo de algodão em vacas mestiças Holandês x Zebu em lactação. R. Bras. Zootec., 24(6):10161026.

BHATTACHARYA, A.N., KHAN, A.R. 1973. Wheat straw and urea in pelleted rations for growing - fattening sheep. J.Anim. Sci., 37(1):136-140.

BORGES, A.L.C.C. 1999a. Controle da ingestão de alimentos. Cad. Téc. Esc. Vet. UFMG, 27:67-79.

BORGES, A.L.C.C. Experiência na condução de um sistema intensivo de produção de leite, com ênfase nos aspectos nutricionais. In: SIMPÓSIO MINEIRO DE NUTRIÇÃO DE GADO DE LEITE, 2, Belo Horizonte, 1999. Anais ... Belo Horizonte, 1999b. p.22-38.

BRODERICK, G.H. Silage extract protocol. Madison, USA. 1998. (Comunicação pessoal).

CANNAS, A., PES, A., MANCUSO, R. 1998. Effect of dietary energy and protein concentration on the concentration of milk urea nitrogen in dairy ewes. J. Dairy Sci., 81(2):499-508.

CHALUPA, W.C.A., BAILE, C.A., McLAUGHLIN, C.L. et al. 1979. Effect of introduction of urea on feeding behavior of Holstein heifers. J. Dairy Sci., 62(8):1278-1284.

COCHRAN, R.C., ADAMS, D.C., WALLACE, J.D. et al. 1986. Predicting digestibility of different diets with internal markers: evaluation of four potential markers. J. Anim. Sci., 63:1476-1483.

CONRAD, H.R. 1966. Symposium on factors influencing the voluntary intake of herbage by ruminant: physiological and physical factors limiting feed intake. J. Anim. Sci., 25:227-235.

CRAIG, W.M., HONG, B.J., BRODERICK, G.A. et al. 1984. In vitro inoculum enriched with particle associated microorganisms for determining rates of fiber digestion and 
protein degradation. J. Dairy Sci., 67:2902-2904.

EKINCI, C., BRODERICK, G.A. 1997. Effect of processing high moisture ear corn on ruminal fermentation and milk yield. J. Dairy Sci., 80(12):3298-3307.

HOLTER, J.B., COLOVOS, N.F., DAVIS, H.A. et al. 1968. Urea for lactating dairy cattle. III. Nutritive value of rations of corn silage plus concentrate containing various levels of urea. J. Dairy Sci., 51(8):1243-1248.

HUBER, J.T., KUNG, L. 1981. Protein and nonprotein nitrogen utilization in cattle. J. Dairy Sci., 64(6):1170-1195.

HUBER, J.T., COOK, R.M. 1972. Influence of site of administration of urea on voluntary intake of concentrate by lactating cows. J. Dairy Sci., 55(10):1470-1473.

JONKER, J.S., KOHN, R.A., ERDMAN, R.A. 1999. Milk urea nitrogen target concentrations for lactating dairy cows fed according to National Research Council recommendations. J.Dairy Sci., 82(6):1261-1273.

KERTZ, A.F., KOEPKE, M.K., DAVIDSON, L.E. et al. 1982. Factors influencing intake of high urea-containing rations by lactating dairy cows. J. Dairy Sci., 65(4):587-604.

LÓPEZ, J. Uréia em rações para produção de leite. In: URÉIA PARA RUMINANTES, 194, Piracicaba, 1984. Anais... Piracicaba, p.171-194, 1984.

LUCCI, C. S. 1997. Nutrição e manejo de bovinos leiteiros. 1.ed. São Paulo: Manole Ltda. 169p.

MAYER, L.R.R., COELHO DA SILVA, J.F., VALADARES FILHO, S.C. et al. 1997. Rações com diferentes teores de proteína degradada no rúmen, para vacas em lactação. 2. Taxa de passagem, digestibilidade e energia líquida da silagem de milho. R. Bras. Zootec., 26(4):824-831.

MERTENS, D.R. Analysis of fiber in feeds and its uses in feed evaluation and ration formulation. In: SIMPÓSIO INTERNACIONAL DE RUMINANTES, REUNIÃO ANUAL DA SOCIEDADE BRASILEIRA DE ZOOTECNIA, 29, 1992, Lavras. Anais... Lavras: SBZ, 1992. p.188-219.

MERTENS, D.R. 1994. Regulation of forage intake. In: FAHEY JR., G.C. (Ed) Forage quality, evaluation and utilization. Madison: American Society of Agronomy. p.450-493.

NATIONAL RESEARCH COUNCIL - NRC. 1989. Nutrient requirement of dairy cattle. 6.ed. Washington: National Academy. 242p.

OBA, M., ALLEN, M.S. 1999. Evaluation of the importance of the digestibility of neutral detergent fiber from forage: effects on dry matter intake and milk yield of dairy cows. J. Dairy Sci., 82(3):589-596.

PREGNOLATTO, W., PREGNOLATTO, N.P. 1985. Normas analíticas do Instituto Adolfo Lutz - métodos químicos e físicos para análise de alimentos. 3.ed. v.1, São Paulo. p.533.

RAMOS, P.R., PRATES, E.R., FONTANELLI, R.S. et al. 2000. Uso do bagaço de mandioca em substituição ao milho no concentrado para bovinos em crescimento. 2 -digestibilidade aparente, consumo de nutrientes digestíveis, ganho de peso e conversão alimentar. R. Bras. Zootec., 29(1):300-305.

ROSELER, D.K., FERGUNSON, J.D., SNIFFEN, C.J. et al. 1993. Dietary protein degradability effects on plasma and milk urea nitrogen and milk nonprotein nitrogen in holstein cows. J. Dairy Sci., 76(2):525-534.
SANTOS, F.A.P., HUBER, J.T., THEURER, C.B. et al. 1998. Milk yield and composition of lactating cows fed steamflaked sorghum and graded concentrations of ruminally degradable protein. J. Dairy Sci., 81(1):215-220.

SILVA, D.J. 1990. Análise de alimentos (Métodos químicos e biológicos). 2.ed. Viçosa: UFV. 165p.

SKLAN, D., ASHKENAZI, R., BRAUN, A. et al. 1992. Fatty acids, calcium soaps of fatty acids and cottonseeds fed to high yielding cows. J. Dairy Sci., 75(9):2463-2472.

SNIFFEN, C.J., O'CONNOR, C.D., VAN SOEST, P.J. et al. 1992. A net carbohydrate and protein system for evaluating cattle diets. II. Carbohydrate and protein availability. J. Anim.Sci., 70(11):3562-3577.

SNIFFEN, C.J., BEVERLY, R.W., MOONEY, C.S. et al. 1993. Nutrient requirements versus supply in the dairy cow: strategies to account for variability. J. Dairy Sci., 76(10):3160-3178.

SUSMEL, P., SPANGHERO, M., STEFANON, B. 1995. Nitrogen balance and partitioning of some nitrogen catabolites in milk and urine of lactating cows. Livest. Prod. Sci., 44:207-219.

UNIVERSIDADE FEDERAL DE VIÇOSA - UFV . 1998. SAEG - Sistema de análises estatísticas e genética. Versão 8.0. Viçosa, MG. (Manual do usuário). 150p.

VAGNONI, D.B., BRODERICK, G.A., CLAYTON, M.K. et al. 1997. Excretion of purine derivatives by Holstein cows abomasally infused with incremental amounts of purines. J. Dairy Sci., 80(8):1695-1702.

VALADARES FILHO, S.C., BRODERICK, G.A., VALADARES, R.F.D. et al. 2000. Effect of replacing alfalfa silage with high moisture corn on nutrient utilization and milk production. J. Dairy Sci., 83(1):106-114.

VAN SOEST, P.J. 1994. Nutritional ecology of the ruminants. 2.ed. Ithaca: Cornell University. 476p.

WILSON, G., MARTZ, F.A., CAMPBELL, J.R. et al. 1975. Evaluation of factors responsible for reduced voluntary intake of urea for ruminants. J. Anim. Sci., 41(5):1431-1437.

WOHLT, J.E., CLARK, J.H. 1979. Nutritional value of urea versus performed protein for ruminants. I. Lactation of dairy cows fed corn based diets containing supplemental nitrogen from urea and/or soybean meal. J. Dairy Sci., 61(7):902-915.

WOODFORD, J.A., JORGENSEN, N.A., BARRINGTON, G.P. 1986. Impact of dietary fiber and physical form on performance of lactating dairy cows. J. Dairy Sci., 69(4):1035-1047. 